\title{
Hypnosis in psychiatry
}

\author{
V. M. Mathew, Lecturer in Psychiatry, University of Leicester, Clinical Sciences \\ Building, Leicester Royal Infirmary, Leicester LE2 7LX
}

\section{Historical background}

This paper aims to give a very brief outline of the vast subject of hypnosis in the context of psychiatry. The word hypnosis, which was derived from Hypnos meaning the God of sleep, has long been associated with magical practices, superstition, witchcraft, occult and many other esoteric practices. The forerunner of hypnosis was the theory of animal magnetism proposed by Franz Anton Mesmer in the 1770s. He began to experiment with magnetic metals and gradually elaborated the theory of animal magnetism. According to Mesmer, a magnetic fluid spread throughout the entire universe and its disturbed balance in the human body resulted in illness. He claimed that a beneficial magnetic fluid could be transmitted from one subject to another by 'passes'. Braid (1843) refuted the fluidist theory, since according to him hypnosis could be induced by visual fixation. He believed the condition to be a form of sleep and called the technique neurypnology, later to become hypnology and hypnosis. Liebeault (1866) for the first time used verbal suggestion to induce hypnosis. Bernheim stated that "There is no such thing as hypnotism, there is only suggestibility", and concluded that suggestibility was the process by which the brain "accepts the idea and transforms it into action".

Later in 1878 the eminent French neurologist Charcot became interested in hypnosis and convinced the French academies of the reality of hypnotic phenomena. Around this period Breuer, a general practitioner in Vienna, accidentally found that when one of his patients was prompted to speak freely under hypnosis, she displayed a profound emotional reaction subsequently resulting in disappearance of most of the symptoms. Breuer drew Freud's attention into hypnosis. Freud joined Breuer in the investigation and they used regression under hypnosis to recall buried memories of repressed traumatic experiences which acted as the cause of emotional difficulties. Freud later abandoned hypnosis, since he was unable to induce deep trance state in many of his patients and the respect of hypnosis declined following Charcot's death. There was a renewed interest in hypnosis during the first world war. Hypnotherapy was once again revived by Hadfield, Wingfield and McDougall and was used both for direct symptom removal and for the restoration of repressed traumatic experiences in the treatment of soldiers suffering from what was then known as "shell shock". Credit goes to Milton $\mathrm{H}$. Erickson, an American psychiatrist who explored and demonstrated the vast potentials of hypnosis in treating a considerable range of medical and psychological disorders. In 1955 the British Medical Association officially rehabilitated hypnosis in Great Britain and in 1958 the American Medical Association integrated hypnosis into medical therapeutics.

There has been a steady expansion of interest in the scientific understanding and application of hypnosis. During recent years several professional hypnosis societies have been established in several countries and most of these are affiliated to the International Society of Hypnosis. An international congress of hypnosis and psychosomatic medicine is held every three years. The European Society of Hypnosis in psychotherapy and psychosomatic medicine also organises a congress every three years.

In the United Kingdom, the British Society for Medical and Dental Hypnosis, the British Society for Experimental and Clinical Hypnosis and various other societies arrange regular conferences and training courses for their members. Recently, the Department of Psychiatry at the University of Sheffield started a Diploma course in Clinical Hypnosis, the only one of its kind on a University level.

\section{Concepts of hypnosis}

It is not known exactly as to when the word "hypnosis" appeared in the literature. The Grand Dictionnaire Universel Larousse gives it for the first time in the 1865-90 edition with the following definition: "sleep induced especially by prolonged fixation of bright objects". The definition given in the report of the British Medical Association states that hypnosis is "a temporary condition of altered attention in the subject which may be induced by another person and in which a variety of phenomena may appear spontaneously or in response to verbal or other stimuli. These phenomena include alterations in consciousness and memory, increased susceptibility to suggestion and the production in the subject of responses and ideas unfamiliar to him in his usual state of mind. Further phenomena such as anaesthesia, paralysis and rigidity of muscles, and vasomotor 
changes can be produced and removed in the hypnotic state".

There are no comprehensive theories explaining hypnosis. Some people regard "hypnosis" as a state, and "hypnotism" as a collection of techniques for producing the state. Some consider that hypnosis is due to suggestion, while others favour the existence of a specific hypnotic state resting upon an almost physical basis. Janet believed that there is a close association between hysteria and hypnosis since phenomena such as fugues and multiple personalities were thought to be due to splitting of consciousness, resulting in the unconscious mind becoming dominant, and proposed that hypnosis is based on dissociation of the mind. Kretschmer considered that hypnosis can actually be separated into its constituent neurophysiological and psychophysiological mechanisms. Hypnotic trance is a labile and dynamic state which changes from one session to the next according to the circumstances of the clinical situation. Hilgard (1977) proposed the neodissociation theory of hypnosis based on his observation that in many subjects, part of the mind is not within awareness appeared to be watching the subject's whole experience. $\mathrm{He}$ coined the term "the hidden observer" to represent this mental structure which monitors everything that happens, including events that the hypnotised subject is not consciously aware of perceiving while under hypnosis.

Barber $(1963,1965)$ reported numerous studies to show that the concept of hypnosis was superfluous, and stated that the behaviour ordinarily subsumed under the label hypnosis could be accounted for with such variables as increased motivation, expectations and performance skills. However Orne \& Evans (1965) showed that compliance with the instructions in apparently dangerous situations was not necessarily a function of hypnosis, and the myth that hypnosis increases compliance began to crumble. The source of the change in behaviour was not the hypnotist, and the causes had to be found in the subject or in the situation. It is currently appropriate to regard hypnotisability as a trait, a disposition carried around by the person and activated in the hypnosis situation. A hypnotised person can be considered as performing a role, and under appropriate conditions, a person could behave as if he or she were deaf or amnesic or analgesic, the role being continuously defined by the hypnotist and interpreted by the subject in terms of his or her prior experiences, beliefs and needs.

In conclusion, modern hypnotherapy bears little relation to the popular presentation of stage hypnosis. Therapeutic hypnosis is the utilisation of the altered state of awareness to channel the untapped resources of the unconscious mind to achieve therapeutic change. The induction and maintenance of the altered state, usually called a trance, serves to provide a special psychological state in which a person can re-associate and reorganise his inner psychological complexities and utilise his own capabilities.

\section{Current state of hypnosis in psychiatry}

The growing interest in hypnosis has led to the investigation of the efficacy of hypnosis as a therapeutic technique in a wide range of psychosomatic disorders (Waxman et al, 1989). As a result of this there have been considerable developments in the theoretical, experimental and clinical aspects of the hypnotic phenomena. However, hypnotherapy has failed to achieve an established role in psychiatry, despite its usefulness in treating psychiatric illnesses other than the major psychoses. This reflects the lack of interest, awareness and lack of training resulting in the fear of the unknown, even among psychiatrists. It is sad to see patients referring themselves in increasing numbers to so-called practising hypnotherapists, the great majority of whom have no medical qualification and, more importantly, no formal training in the fields of psychology and psychiatry.

In spite of tremendous developments in various fields of psychiatry, it is widely accepted that there are still defects in the provision of holistic care for the mentally ill. Understanding of human brain anatomy, physiology and biochemistry has helped us to develop new pharmacological agents with relative specificity in their mode of action. However, pharmacotherapy is not without its pitfalls, although it is well established, especially in the treatment of major psychosis, that drugs alleviate some of the symptoms. Nevertheless drugs seldom provide complete recovery and have been found to be quite ineffective in minor depressive and varieties of neurotic illnesses. Hence the advent of various psychotherapeutic approaches which are being used singly or in combination with drug therapy.

\section{Conclusion}

It is increasingly recognised that patients treated by psychiatrists are not satisfied with pharmacotherapy alone, as it seldom improves the overall quality of life. Hypnosis is a very valuable form of therapy, especially in liaison psychiatry, since patients referred to psychiatrists by the specialist who sees the patient for primary problems might have investigated the patient fully and excluded all possible organic causes that could explain the presenting symptomatology. Many of the problems and illnesses contain a large psychological element, which may prolong the symptoms long after one would expect them to be resolved. Understanding and 
altering the psychological component provides a simple and brief way to overcome a troublesome situation.

The goal of psychiatrists should be to help patients to understand the nature of their problems and to weigh the benefits and the costs of the available therapeutic alternatives. In order to do this it is appropriate for psychiatrists to have an adequate working knowledge about each of the currently available forms of intervention, its indications and contra indications, so that therapy can be tailored to suit the needs of individual patients rather than trying to fit the patient into the mode of therapy which is convenient to the therapist. Hypnotherapy should be considered as a supportive and supplementary therapy and not as a substitute form of therapy to treat the untreatable.

\section{Acknowledgements}

I wish to thank Dr S. Bhaumik and Dr D. Bramble for their contribution to this paper.

\section{References}

Barber, T. X. (1963) The effects of hypnosis on pain: a critical review of experimenal and clinical findings. Psychological Medicine, 25, 303-333.

- (1965) The effect of hypnosis on learning and recall: a methodological critique. Journal of Abnormal Psychology, 21, 19-25.

BraID, J. (1843) Neurypnology London: Churchill.

Hilgard, E. R. (1977) Divided consciousness: multiple controls in human thought and action. New York: WileyInterscience.

LIEBEAULT, A. A. (1866) Du sommeil et des etats analogues consideres surtout au point de vue de l'action du moral sur le physique. Paris: Masson.

ORNe, M. T. \& Evans, F. J. (1965) Social control in the psychological experiment: antisocial behavior and hypnosis. Journal of Personality and Social Psychology, 1, 189-200.

Waxman, D., Pedersen, D., Wilkie, I. \& Mellett, P. (1989) Hypnosis: The Fourth European Congress at Oxford. London: Whurr Publishers.

A full list of references is available on request from $\mathrm{Dr}$ Mathew.

Psychiatric Bulletin (1993), 17, 204-206

\title{
The Access to Health Records Act: what difference does it make?
}

\author{
Robert E. Butler, Registrar, Department of Child and Adolescent Psychiatry; and \\ DASha E. Nicholls, Registrar, Department of Psychiatry, University College \\ Hospital and Middlesex School of Medicine, London W1N 8AA
}

\begin{abstract}
The Access to Health Records Act came into force on 1 November 1991. This legislation allows patients access to their written medical records (access to computerised records is covered by separate legislation). Concerns have been expressed about the implications of this Act for staff and patients, particularly in psychiatry. These concerns have included detrimental effects on patients exposed to their notes and the restrictions it could place upon staff in recording speculation or subjective opinion. We report the following findings: staff attitudes to the new legislation including awareness of the Act, evaluation of the Act as useful or detrimental and the Act's implications on clinical practice.
\end{abstract}

\section{The study}

A 70 item questionnaire was sent to all full-time qualified staff working in the department of psychiatry in a district general hospital (Princess Alexandra Hospital, Harlow, Essex $)(n=102)$.

The questionnaire was developed following a pilot study with two earlier versions. It is designed to assess staff attitudes to The Access to Health Records Act and includes issues raised both in the Danish literature (Svendsen \& Toftegaard, 1989; Andersen \& Jorgensen 1989) and English literature (Bernadt et al, 1991; McShane et al, 1992). The questionnaire includes open and closed questions. 